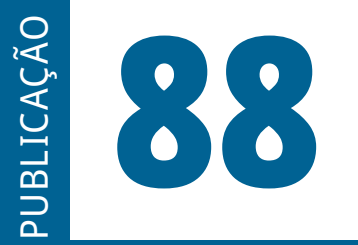

ISSN: 0101-9562

ISSN ELETRÔNICO: 2177-7055

SEQÜÊNCIA

Publicação do

Estudos jurídicos

e políticos

Programa de Pós-Graduação em Direito da UFSC

VOLUME 42 - ANO 2021 
SEQUÊNCIA - ESTUDOS JURÍDICOS E POLÍTICOS é uma publicação temática e de periodicidade quadrimestral, editada pelo Programa de Pós-Graduação Stricto Sensu em Direito da Universidade Federal de Santa Catarina - UFSC.

SEQUÊNCIA - ESTUDOS JURÍDICOS E POLÍTICOS is a thematic publication, printed every four months, edited by the Program in law of the Federal University of Santa Catarina - UFSC.

Versão eletrônica: http://www.periodicos.ufsc.br/index.php/sequencia

A publicação é indexada nas seguintes bases de dados e diretórios/

The Publication is indexed in the following databases and directories:

Base OJS

Base PKP

CCN (Catálogo Coletivo Nacional)

Dialnet

DOAJ (Directory of Open Access Journals)

EBSCOhost

Genamics Journalseek

ICAP (Indexação Compartilhada de Artigos de Periódicos)

Latindex

LivRe!

OJS
PKP
Portal de Periódicos UFSC
Portal do SEER
ProQuest
SciELO
Sherpa/Romeo
Sumarios.org
ULRICH'S
vLex

Ficha catalográfica

Seqüência: Estudos jurídicos e políticos. Universidade Federal de Santa Catarina.

Programa de Pós-Graduação em Direito. n.1 (janeiro 1980)-.

Florianópolis: Fundação José Boiteux. 1980-.

Publicação contínua

Resumo em português e inglês

Versão impressa ISSN 0101-9562

Versão on-line ISSN 2177-7055

1. Ciência jurídica. 2. Teoria política. 3. Filosoia do direito. 4. Periódicos.

I. Universidade Federal de Santa Catarina. Programa de Pós-graduação em

Direito

CDU 34(05)

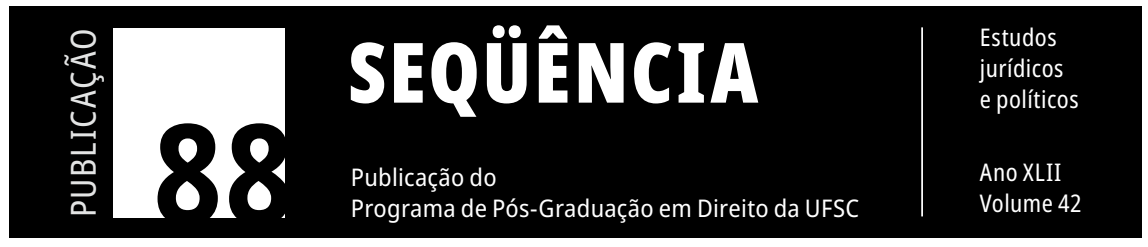




\title{
Mulher e voz: os desafios à efetividade dos direitos políticos femininos
}

\author{
Women ad voice: the challenges to \\ women's political rights effectiveness
}

Luana Mathias Souto

Pontifícia Universidade Católica de Minas Gerais, Belo Horizonte, Brasil

José Adércio Leite Sampaio

Pontifícia Universidade Católica

de Minas Gerais, Belo Horizonte, Brasil

ReSUMO: O presente artigo tem por objetivo brevemente demonstrar como o histórico silenciamento da voz feminina em espaços públicos reverbera na severa sub-representação feminina na política, adotando-se a perspectiva de que a historicidade da construção das figuras de poder em diversos contextos é, ao lado de outros elementos, definidor da baixa representatividade feminina na política. Para tanto, este estudo adota a metodologia de revisão bibliográfica e análise de relatórios de pesquisas desenvolvidas sobre o assunto que apresentam dados estatísticos sobre essa realidade, bem como a utilização de exemplos atuais e históricos que demonstram os diversos contornos práticos dos obstáculos vivenciados pelas mulheres na busca por efetiva igualdade de acesso aos espaços de poder. Ao final, conclui-se que os direitos políticos das mulheres no Brasil não possuem efetividade, tornando-se necessária e urgente a modificação desse cenário.

PalavRAS-Chave: Representação Política - Mulheres - Direitos Políticos - Efetividade. ABSTRACT: This article briefly aims to demonstrate how the historical silencing of the female voice in public spaces reverberates in the severe women under-representation in politics, adopting the perspective that the historicity of the construction of power's figures in different contexts is, alongside other elements, something that defining the low female representation in politics. Therefore, this study adopts 
the methodology of literature review and analysis of research reports developed about the subject with statistical data about it, as well as the use of current and historical examples that demonstrate the various practical contours of the obstacles experienced by women in search for effective equality of access to spaces of power. In the end, it is concluded that women's political rights in Brazil are not effective, and it's necessary and urgent to change this.

KEYWORDS: Political representation - Women - Political rights - Effectiveness.

\section{INTRODUÇÃO}

O presente artigo tem por objetivo demonstrar como o histórico silenciamento da voz feminina em espaços públicos reverbera na atual severa sub-representação feminina na política.

Remando contra a maré do desenvolvimento intelectual, econômico e político que se vive no século XXI os últimos anos da década de 2010 apresentaram significativo retrocesso no tratamento às mulheres, principalmente, para aquelas que se encontram democraticamente eleitas e ocupando os principais espaços de tomada de decisões.

A cisão biopolítica dos direitos políticos das mulheres, a partir de uma análise a luz da teoria desenvolvida por Michel Foucault (2008) e aprimorada por Giorgio Agamben (2002), em que os corpos femininos são relegados ao seu aspecto meramente biológico, sendo as mulheres social e culturalmente percebidas como meras urnas desenvolvedoras de vida humana, cujo único destino na vida é reproduzir, demonstra que mesmo sob o amparo de textos constitucionais com anseios mais igualitários há a inefetividade - evidente e também sutil - dos direitos de votar e ser eleita.

Quanto a essa segunda parte dos direitos políticos - ser eleita - mulheres em diversos contextos enfrentam o mesmo problema, que apesar de se ter seus contornos moldados aos locais onde estão inseridas, manifesta-se sobre a mesma (histórica) intenção: afastá-las dos espaços de poder.

Assim, por meio da metodologia de revisão bibliográfica serão analisados textos escritos por pesquisadores estrangeiros e brasileiros, 
tais como a historiadora britânica Mary Beard (2017), a cientista política canadense Manon Tremblay (2007), a consultora independente ruandesa Justine Uvuza (2014) e as juristas brasileiras Luana Souto e Clarice Morais (2018); relatórios de pesquisas desenvolvidas pela organização internacional, Inter-Parliamentary Union (IPU), pela Fundação Getúlio Vargas (FGV) e pelo Instituto Alziras, além da análise de exemplos atuais de mulheres políticas e seus desafios na condução da vida pública, cujo intento desse debate transdisciplinar é demonstrar que a historicidade aplicada à construção das figuras de poder em diversos contextos é, ao lado de outros elementos, definidor da atual baixa representatividade feminina na política.

Dessa forma, no tópico i) Privado versus público: biopoder em ação evidencia-se, a partir dos estudos desenvolvidos por Michel Foucault (2008) e Giorgio Agamben (2002) a cisão biopolítica entre o direito de votar e o direito de ser eleita, diante do embate histórico vivido pelas mulheres entre vida pública e vida privada. Por meio dessa cisão, na atualidade, ainda que com a consolidação dos direitos políticos, evidencia-se que votar é possível, mas ser eleita é um desafio em efetividade, já que o histórico processo de silenciamento da voz feminina interfere no gozo desse direito ainda nos dias de hoje. O tópico ii) Representação descritiva versus representação substantiva: como as mulheres alteram a política?, por sua vez, apresenta as contribuições da teoria da representação desenvolvida por Hanna Pitkin (1985) com a finalidade de demonstrar que, superados os desafios iniciais para serem eleitas, as mulheres quando acessam esses espaços ainda enfrentam diversos obstáculos para transformar suas presenças, seja no Executivo ou no Legislativo, em verdadeiras pautas em prol dos direitos femininos, visto que ao longo de seus caminhos elas também encontram armadilhas criadas pelo patriarcado sobre como uma mulher no poder deveria ser.

Por fim, o tópico iii) Mulheres na política: panorama nacional e internacional traz à tona, sob as perspectivas negativas e positivas, exemplos de representação feminina a partir de contextos diversos. À luz da primeira perspectiva, colaciona-se relatos de mulheres que, apesar de democraticamente eleitas em países latino-americanos e 
europeus, convivem com a violência política de gênero numa tentativa patriarcal de removê-las de seus mandatos políticos. A segunda perspectiva, todavia, é colacionada ao texto no desejo de que novas vivências políticas possam alcançar as mulheres para que enfim, seus direitos políticos ganhem efetividade.

\section{PRIVADO VERSUS PÚBLICO: BIOPODER EM AÇÃO}

A frase dita por Telêmaco à sua mãe Penélope reverbera até hoje no imaginário comum e ainda que de forma inconsciente é, em parte, responsável pela dificuldade até mesmo em países desenvolvidos de se conceber que às mulheres devem ser conferido espaço na vida política (BEARD, 2017).

A Odisséia narra que após a saída de Ulisses para além-mar, Telêmaco, seu filho com Penélope, ordena a mãe que se recolha ao seu quarto e aos seus afazeres domésticos, pois a palavra importava aos homens; "mormente a [ele] [...], a quem cumpre assumir o comando da casa.” (Homero, 2001, p. 37-38). Ulisses estava em viagem em direção a Guerra de Troia e podia não mais regressar. Telêmaco, portanto, assume para si o comando da casa diante de uma proposta silenciadora de sua mãe que perpetua no tempo (BEARD, 2017).

Pelo exemplo de Telêmaco observa-se que bios e zo $\grave{e}^{1}$ em sua discernibilidade não se comunicam na vida feminina, de forma que Penélope pelo silenciamento obrigado pelo filho permanece apenas

\footnotetext{
Segundo Giorgio Agamben (2002) “os gregos não possuíam um termo único para exprimir o que nós queremos dizer com a palavra vida. Serviam-se de dois termos, semântica e morfologicamente distintos, ainda que reportáveis a um étimo comum: zoe, que exprimia o simples fato de viver comum a os seres vivos (animais, homens e deuses) e bios, que indicava a forma ou maneira de viver própria de um indivíduo ou de um grupo. Quando Platão, no Filebo, menciona três gêneros de vida e Aristóteles, na Ethica nicomachea, distingue a vida contemplativa do filósofo (bios theoreticos) da vida de prazer (bios apolausticos) e da vida política (bios politicós), eles jamais poderiam ter empregado o termo zoe (que, significativamente, em grego carece de plural) pelo simples fato de que
} 
em sua zoè, não atingindo o status de zoon politikòn ${ }^{2}$, não adentrando a vida política, pois o muthos ${ }^{3}$ lhe foi negado pelo próprio filho (Agamben, 2002; BeArd, 2017).

Assim, remanesce para Penélope a condição de ser vivente aprisionada ao espaço eminentemente privado. Sem voz pública, sem voz política, em um processo que historicamente coloca as mulheres "em situação jurídica e política de inferioridade, dando azo a opressões no ambiente privado e a exclusões na esfera pública." (SAMPAIO, 2010, p. 304).

Avançando-se alguns séculos, expressões hoje conhecidas como: mansplaining ${ }^{4}$, manterrupting ${ }^{5}$ e bropriating ${ }^{6}$ representam exatamente a

para ambos não estava em questão de modo algum a simples vida natural, mas uma vida qualificada, um modo particular de vida." (AGAMBEN, 2002, p. 09).

2 Aristóteles, em Política, estabelece que "o homem é o patriarca e senhor por natureza porque, sendo zoon politikon, é aquele capaz de deliberar sobre o que diz respeito à reprodução e à preservação da vida. [...] O homem também é naturalmente mais apto a mandar do que a mulher; por isso governa a casa e os filhos do mesmo modo que o mais velho está mais apto a mandar do que o mais novo e menos desenvolvido. Todos estes se encontram submetidos à autoridade patriarcal porque não são plenamente livres para governarem a si mesmos." (FEOLA, 2012, p. 45)

3 “'When he says 'speech' is 'men's business', the word is muthos - not in the sense that it has come down to us of 'myth'. In Homeric Greek it signals authoritative public speech, not the kind of chatting, pratting or gossip that anyone - women included, or especially women - could do," (BEARD, 2017, p. 06).

4 Termo originário da junção das palavras inglesas man (homem) e explaining (explicação), que consiste no ato de um homem interromper uma mulher para explicá-la algo que ela já sabe. Em 2008, Rebecca Solnit escreveu o artigo Homens explicando coisas para mim, onde ela definiu mansplaining quando um homem interrompe uma mulher para explicá-la algo que na verdade ela sabe mais do que ele. Ela narra uma experiência quando um homem uma vez a interrompeu para dizê-la sobre um importante livro que estava em voga sem perceber que o livro que ele estava dizendo a Rebecca... era o livro da Rebecca (REEVES, 2015).

5 Termo originário da junção das palavras inglesas man (homem) e interrupting (interromper), que significa as diversas interrupções desnecessárias feitas por homens quando mulheres estão falando. Em 2015, o Time publicou um artigo explicando o termo manterrupting e bropropriating, diante da interrupção realizada por Kanye West durante discurso de Taylor Swift no VMA 2009 (REEVES, 2015).

6 Termo originário da junção das palavras bro-, prefixo de brother (irmão) e apropriating (apropriação), que significa quando um homem leva o crédito por uma ideia de uma mulher. O termo foi cunhado na mesma época que manterrupting (REEVES, 2015). 
atitude pseudo-condescendente de Telêmaco. Sua ação é, portanto, fruto de uma construção sócio-cultural que visualiza as mulheres como homines sacri ${ }^{7}$ (AgAmBEN, 2002).

De acordo com o Inter-Parliamentary Union (IPU) as mulheres, em 2020, representavam apenas 24,5\% dos assentos nos Parlamentos pelo mundo. No relatório que celebra os 25 anos desde a realização da IV Conferência Mundial da Mulher em Beijing, a perspectiva apresentada é que o número de mulheres nos Parlamentos desde então, dobrou. Entretanto, com exceção da Europa todas as demais regiões analisadas (Pacífico, Américas, Ásia e África) possuem países em que a participação feminina é menor do que $5 \%$.

No cenário nacional, segundo dados das últimas eleições ocorridas em 2018 foram eleitas 77 deputadas federais e 07 senadoras (Barbieri; Ramos, 2019, p. 28). De forma que em 25 anos, apesar do número de mulheres eleitas para a Câmara dos Deputados ter dobrado, sendo que em 1995 elas representavam apenas 7\% e em 2018 representavam 14,6\% (IPU, 2020), os parâmetros se encontram abaixo do esperado, principalmente, quando considerado que para as Nações Unidas e a IPU a proposta é de que até 2030, a representação feminina a patamares se traduza em paridade de gênero.

No Brasil, o projeto de aceleramento da participação feminina com vistas a paridade de gênero já se encontra em funcionamento desde 2019 por meio da aplicação do mecanismo ATENEA, desenvolvido em parceria entre o Centro Regional do PNUD para a América Latina e Caribe, a ONU Mulheres e a IDEA Internacional, que além de medir os índices nacionais e comparativos da América Latina de compromissos com a igualdade na legislação; o exercício do direito ao voto; a existência de políticas afirmativas; a presença de

Termo em latim que designa o "homem sacro [...] aquele que o povo julgou por um delito; e não é lícito sacrificá-lo, mas quem o mata não será condenado por homicídio; na verdade, na primeira lei tribunícia se adverte que "se alguém matar aquele que por plebiscito é sacro, não será considerado homicida". Disso advém que um homem malvado ou impuro costuma ser chamado sacro.” (AGAMBEN, 2007, p. 196). 
mulheres no Executivo, Administração Pública, Legislativo, partidos políticos e governos locais também propõe metas e compromissos com a finalidade de melhorar esses índices e, assim, a longo prazo atingir a paridade de gênero (ONU Mulheres, 2020).

Essa sub-representação feminina, todavia, não é sem propósito. Faz parte do processo de negação histórica de acesso às mulheres aos espaços de poder, que se consubstancia na Modernidade em uma política implícita de governo que prima pelo corpo biológico em detrimento dos desejos, anseios e vontades femininas. A partir daquilo que Michel Foucault (2008), identifica por biopoder: “o conjunto dos mecanismos pelos quais [...] as sociedades ocidentais modernas, a partir do século XVIII, voltaram a levar em conta o fato biológico fundamental de que o ser humano constitui uma espécie humana." (Foucault, 2008, p. 03).

Sob essa perspectiva, o aspecto biológico que difere as mulheres dos homens; sua capacidade reprodutiva singular de gestar outro ser humano, possui mais valor do que a garantia dos seus direitos, pois existe um valor intrínseco a este aspecto biológico que é notadamente precioso para o Estado. Por meio de técnicas de investimento na tecnologia da vida, o Estado aperfeiçoa seu capital humano, passo que é necessário para a construção de sua riqueza, que não mais se pauta nas dimensões territoriais conquistadas e sim, no crescimento populacional (Foucault, 2008; 2008a).

O Projeto de Lei n. 102, de 1919, encabeçado pelo Senador Justo Chermont é exemplificativo dessa forma biopolítica pela qual o corpo feminino, e não apenas a sua voz, é encarado e afastado do seio político, pois com a finalidade de implementar o direito ao voto feminino, apresenta a seguinte justificação: "prestando a devida homenagem a principal missão da mulher sobre a terra - os misteres da maternidade - penso que eles não são incompatíveis com os seus deveres sociais e com os direitos políticos que o regime democrático lhe deve garantir.” (Nunes; Bonini, 2010, p. 10, grifo nosso). 
O referido Projeto de Lei surge diante da onda de movimentos sufragistas pelo mundo que pugnavam pelo direito igualitário ao voto. Contudo, observa-se que apesar de haver o empenho do Senador Justo em apoiar a causa feminina, esse empenho se justifica tão somente porque não há compatibilidade entre o direito ao voto e o exercício do "dever", assim entendido à época, da maternidade, que se constitui como elemento biológico de diferenciação entre homens e mulheres. Entretanto, o direito a ser eleita, por sua vez, sob a lógica biopolítica não poderá ser encarado da mesma forma, e por isso, os altos índices de sub-representação feminina na política mesmo em países mais desenvolvidos. Pois, o exercício da vida política, em oposição ao direito ao voto exige de seus atores voz e ação, o que é negado às mulheres desde a Grécia Antiga, como observado no exemplo de Telêmaco e Penélope ${ }^{8}$.

Assim, alegar a existência de direitos políticos femininos no Brasil torna-se discurso falacioso, pois enquanto votar é obrigatório a todos e pode ser exercido pelas mulheres sem prejuízo "aos misteres da maternidade" (NunEs; Bonini, 2010, p. 10). Ser eleita representa vencer obstáculos não normativos, pois existe uma realidade social, política e econômica que inviabiliza sua efetividade em vários graus. Quando se trata de efetividade, nesta segunda parte dos direitos políticos femininos, o direito de ser eleita, ser e dever-ser se desconectam, pois enquanto o texto constitucional diz que todos são iguais, a realidade demonstra que as mulheres possuem muito mais desafios fáticos para serem eleitas do que os homens.

No Brasil, quando em 1930 se instituiu o direito ao sufrágio universal também foi conferido às mulheres brasileiras o direito a serem

Luis Antonio Corona Nakamura e Eneida Desiree Salgado (2020), sobre o assunto relembram que durante o Segundo Império, a Princesa Isabel que aos olhos da Constituição de 1824 poderia assumir o trono, foi inviabilizada de também assumir a função de Senadora. Prerrogativa que, à época, era concedida aos príncipes, mas que, segundo José de Alencar, não poderia ser assumida pela princesa, pois as mulheres não possuíam capacidade política que permitisse a responsabilização exigida ao cargo Senador. 
eleitas, ainda que culturalmente não fosse fomentado o exercício desse direito e por isso, alega-se que o exercício dos direitos políticos femininos em absoluto ser garantido pelo ordenamento jurídico brasileiro é discurso falacioso, pois não se criou historicamente mecanismos que viabilizassem o exercício de suas duas dimensões (votar e ser eleita). Outras experiências latino-americanas demonstram como o bojo do direito político pode ser normativamente bipartido. "O direito de ser eleita, entretanto, nem sempre foi garantido de forma simultânea: na Bolívia e El Salvador, por exemplo, a capacidade de exercer essas funções vieram décadas depois do direito de voto9." (Hinojosa; PisCOPO, 2013, p.01, tradução nossa).

Em outra dimensão, os direitos políticos são bipartidos de forma não normativa, quando por meio da suspensão da efetividade da lei torna-se necessário a criação, por exemplo, das cotas de gênero difundidas especialmente a partir da IV Conferência Mundial sobre a Mulher das Nações Unidas realizada em Beijing, em 1995.

A IV Conferência, inclusive inspirou a implantação das cotas de gênero no Brasil, que inicialmente surgiu apenas para as eleições municipais, mas que em 1997 foram ampliadas para as eleições federais, com a finalidade de conferir efetividade a um mandamento normativo há muito existente.

Assim, as cotas de gênero ${ }^{10}$, que no Brasil são restritas às candidaturas para o Legislativo, têm por objetivo ampliar a participação feminina na tomada de decisões e concretizar os ideais emanados em Beijing, em 1995. Entretanto, após 25 anos de utilização das cotas de gênero os resultados apresentados em termos de representação política estão longe do ideal de igualdade.

9 The right to be elected, however, was not always guaranteed simultaneously: in Bolivia and El Salvador, for instance, the ability to hold office came several decades after the ability to vote. (HINOJOSA; PISCOPO, 2013, p.01).

10 Segundo Manon Tremblay (2007) a participação feminina na política depende em grande do engajamento dos partidos políticos em promovê-la. Por essa razão, as cotas de gênero são impostas aos partidos políticos. 
Além disso, no Brasil a política de cotas sofre os efeitos do fenômeno conhecido por "candidaturas fantasmas ${ }^{11}$ ", quando mulheres se candidatam ao pleito, mas não recebem nem o próprio voto, com o único objetivo de que os partidos políticos cumpram a exigência de $30 \%$ das candidaturas femininas. Diante disso, observa-se que o mecanismo da cota de gênero criado no País impõe apenas que mais mulheres sejam candidatas, mas não que mais mulheres sejam eleitas e por isso, o cálculo esperado, de redução das desigualdades na participação das decisões políticas não ocorre, ou pelo menos, não imediatamente.

Manon Tremblay (2007) em estudo que demonstra as variáveis que interferem no número de mulheres nos Parlamentos analisa como países de democracia livre por mais de metade do tempo durante o período de 1972 a 2003 e países de democracia livre a menos da metade do tempo durante o mesmo período são afetados por fatores culturais, socioeconômicos e políticos quando o tema é participação feminina nas legislaturas.

Desde o início, o estudo alerta que analisar empiricamente a democracia é algo complexo, heterogêneo e multifacetado, de forma que diversas variáveis (combinadas ou não) podem interferir nos motivos pelos quais cada país tem seu número de representantes femininas.

Manon Tremblay (2007), portanto, apresenta a partir de dados empíricos, as seguintes conclusões:

a) Os indicadores variam de acordo com o tempo em que cada país é exposto à experiência democrática, e isso serve para todos. Assim, países com experiência democrática de

11 As candidaturas fantasmas são apenas uma das hipóteses do que se denomina por candidatura laranja, um termo guarda-chuva que abriga também as hipóteses de candidatas como "cordeiro de sacrifício" e candidatas em substituição. Além dessas hipóteses, Kristin Wylie, Pedro dos Santos e Daniel Marcelino (2018) dividem a candidatura laranja em legal e ilegal, sendo que as legais se subdividem em: ingênuas e estratégicas e as ilegais em não consensuais e "em licença". Esta última em alusão a possibilidade de que funcionários públicos recebem licença para concorrer a cargos públicos. 
pelo menos metade do tempo, considerando o período de 1972 a 2003, a variável de concepção equitativa de gênero é o principal fator que explica a proporção de mulheres na política. Mas, a relevância desse aspecto não se aplica para os países com menor exposição democrática durante o mesmo período;

b) Existem variáveis que deveriam ser integradas a análise, mas que não são facilmente adaptadas aos parâmetros estatísticos como, por exemplo, as mobilizações feministas, que influenciam no aumento do número de mulheres na política;

c) Países com pouca exposição democrática, o sistema de voto interfere no número de mulheres eleitas, o que não ocorre nos países com maior exposição. Assim, eleições proporcionais, nesses países, aumentam o número de mulheres e eleições majoritárias desencorajam candidaturas femininas;

d) Em países com maior tempo de exposição à democracia, o tempo em que mulheres possuem o direito ao voto, como também quando a primeira mulher foi eleita não influencia no número de mulheres no Parlamento. Entretanto, em países com menor tempo de exposição democrática, a presença de mulheres presidentes ou primeiras-ministras influencia positivamente no número de mulheres no Parlamento;

e) As cotas de gênero, por sua vez, não possuem significância estatística para determinar a proporção de mulheres na política em países com pouca e em países com maior exposição democrática (Tremblay, 2007, p. 544-548).

As conclusões empíricas propostas por Manon Tremblay (2007) são elucidativas e representam grande avanço na compreensão de algumas medidas utilizadas para o aumento do número de mulheres na política. Contudo, observa-se a partir de seu estudo que a questão da sub-representação feminina na política é cíclica, ainda que se entenda que não existe apenas um fator que a determine. 
O aspecto cíclico desse problema decorre da análise de que se não há social, cultural e politicamente incentivo à igualdade de gênero, não há igualdade de participação política. O maior tempo de exposição à democracia não reflete no aumento do número de mulheres na política, apenas altera quais estratégias precisam ser usadas para aumentá-lo. Assim, países há mais tempo democráticos ou há menos tempo enfrentam o mesmo problema, que faz com que as mulheres retornem ao limbo do confinamento de uma vida essencialmente privada. Permanecendo, portanto, onde Telêmaco deixou Penélope.

A análise, portanto, sobre os desafios à participação feminina na política precisa suplantar o viés patriarcal opressor e criar mecanismos que promovam a real mudança da mentalidade que visualiza apenas os homens como homo politicus. Um sistema que cria um modelo padrão de candidato que tem por características boa oratória, curso superior em carreiras estratégicas como Direito e Administração entre outras habilidades que tornam candidatas mulheres ou, até mesmo candidatos de determinada classe social diversa da esperada pelo modelo dominante, considerados como inviáveis (Tremblay, 2007).

As lições de John Stuart Mill (1874) demonstram que desde o século XVII advogava-se para que as mulheres também tivessem voz política, de forma que o afastamento feminino desses espaços era fator que comprometia a própria noção de Estado e, principalmente, de democracia: "todos os governos permanecerão extremamente imperfeitos, até que cada um que é requerido a obedecer as leis, ter voz, ou uma expectativa de voz em suas deliberações e administração. ${ }^{12}$ " (Mill, 1874, p. 21-22, tradução nossa).

Suas lições não se esgotam nisso, quando em grande vanguarda ao seu tempo, por meio de sua obra $A$ sujeição das mulheres (2006), John

12 "all governments must be regarded as extremely imperfect, until every one who is required to obey the laws, has a voice, or the prospect of a voice, in their enactment and administration." (MILL, 1874, p. 21-22) 
Stuart Mill demonstra como a insistência institucional em negar poder político às mulheres é frágil em suas fundamentações:

É algo estranho que a única coisa existente que a lei exclui mulheres de fazer é aquela que elas provaram que podem fazer! Não existe lei que impeça uma mulher de escrever todas as peças de Shakespeare ou compor todas as óperas de Mozart. Mas, se a Rainha Elizabeth e a Rainha Vitória não tivessem herdado o trono elas não poderiam ser confiadas ao menor dever político - e a quantidade de deveres a qual a Rainha Elizabeth se apresentou é suprema. [...] A História nos apresenta menos rainhas reinantes do que reis, mas o talento para reinar tem sido mostrado por uma proporção maior de rainhas do que reis - considerando o fato que muitas rainhas ocuparam o trono em períodos de dificuldades. É também marcante que elas frequentemente podem ser distinguidas pelo mérito claramente oposto do que o imaginário e a convencionalidade indicam como características femininas: elas são observadas pela firmeza e vigor de seus governos, tanto quanto por sua inteligência (MıLL, 2006, p. 31-32).

Essa contrariedade histórica exposta nas afirmações de John Stuart Mill (2006) revela toda a gama de efeitos deletérios que a dominação masculina provoca para o desenvolvimento social, a partir do momento em que priva as sociedades modernas de acesso a todas as ideias e perspectivas que a compõem.

\section{REPRESENTAÇÃO DESCRITIVA VERSUS REPRESENTAÇÃO SUBSTANTIVA: COMO AS MULHERES ALTERAM A POLÍTICA?}

Hanna Pitkin, na obra O conceito de representação (1985), além de fazer incursão sobre os diversos termos que levaram à compreensão do conceito atual de representação também lança luz sobre a divisão entre representação descritiva e representação substantiva.

Essa divisão da representação em descritiva e substantiva é importante para a compreensão de como a representação política feminina 
possui nuances distintivas entre o número de mulheres eleitas e os efeitos provocados pela presença feminina no lócus decisório, sob os quais a obra de Anne Philips (1998) auxilia na compreensão.

Os estudos realizados por Anne Philips (1998) indicam que a presença feminina na política permite uma melhor representação dos interesses femininos, principalmente, em aspectos como cuidados infantis, educação, trabalho e violência sexual pelo fato de que essas mulheres compartilham das mesmas experiências que as demais ${ }^{13}$. Entretanto, a autora argumenta que eleger mulheres e esperar que consigam atender às pautas femininas é como um "tiro no escuro", uma vez que é extremamente difícil alterar as instituições políticas. $\mathrm{E}$, é sobre esse aspecto que as representações descritiva e substantiva tratam, pois ter muitas mulheres eleitas é diferente de como a presença feminina é capaz de alterar as pautas políticas em prol de interesses femininos (Phillips, 1998).

Para se compreender como a representação feminina gera mudanças na agenda política, estudo realizado pelo Instituto Alziras sobre o Perfil das prefeitas no Brasil: mandato 2017-2020 (2018) revela que saúde, educação e gestão pública são consideradas áreas prioritárias em seus governos (Instituto Alziras, 2018).

Ainda que a presença feminina inspire pautas mais sociais e progressistas ${ }^{14}$, ter mais mulheres no Parlamento nem sempre indica reais mudanças sociais. Segundo o Inter-Parliamentary Union, Ruanda é o primeiro país no mundo em ranking de maior representação feminina

13 Em contraposição, Hanna Pitkin (2006), a partir dos ensinamentos de Burke (1949) conclui que, "uma vez que a relação de cada parlamentar é com a nação como um todo, ele não se encontra numa relação especial com seu eleitorado; ele representa a nação, não aqueles que o elegeram.” (PITKIN, 2006, p. 31). Assim, a presença feminina ainda se mantém importante, pois possui outro olhar sob o mundo e uma nova perspectiva para a nação que representa.

14 Sociedades que elegem mais mulheres tender a ser mais pró-igualdade de gênero. Além disso, maior número de mulheres nos parlamentos indica menores níveis de corrupção, pois o grau de transparência e integridade nessas sociedades elevam as chances de que mulheres alcancem espaços políticos de destaque (WÄNGNERUD, 2009). 
no Parlamento, indicando que 61,25\% dos assentos na Câmara Baixa são de mulheres e $38,46 \%$ dos representantes eleitos no Senado são mulheres. Apesar disso, Ruanda permanece sendo um dos países mais pobres do mundo e o aumento da participação feminina decorre da implantação das cotas de gênero, após o genocídio de 1994 (Ẅ̈NGNERUD, 2009).

Diante da excepcionalidade numérica proporcionada pelo caso de Ruanda, Mary Beard (2017, tradução nossa p. 85) avalia que, “em alguns lugares, a presença de um grande número de mulheres no parlamento significa que aquele parlamento é onde o poder não estát ${ }^{15}$.".

A afirmação de Mary Beard (2017) encontra apoio na análise realizada pela ruandesa Justine N. Uvuza (2014), que explica que a inserção de mulheres no Parlamento não alterou as relações de poder no país. As mulheres eleitas precisam conciliar os postos assumidos e as obrigações que culturalmente lhe são impostas, o que causa acúmulo de funções, visto que as bases patriarcais não foram alteradas a ponto de que a sociedade se tornasse pro-igualdade de gênero.

Por isso, buscar representação substantiva é mais importante do que simplesmente aumentar o número de mulheres eleitas. Ações que apoiam a representação descritiva vem sendo implementadas desde a IV Conferência de Beijing, mas medidas que transformam esses números em realidade fática de verdadeira igualdade de gênero ainda estão por serem construídas.

A bandeira em prol de maior participação feminina, ainda que sobre ela existem diversas nuances de análise, se fundamenta na necessidade de efetividade de um dos princípios fundantes do Estado Moderno que, é a igualdade. Pois, estados democráticos não podem permanecer negando que metade da população do país não tenha igual acesso e voz política, pois isso contraria a premissa de igualdade que tanto clamam e fere a dignidade humana.

\footnotetext{
15 "in some places, the presence of large numbers of women in parliament means that parliament is where the power is not."
} 
A problemática de como as mulheres ao acessar esse espaço poderão ou não provocar mudanças sociais significativas ao gênero feminino e às minorias perpassa por desafios ainda mais sensíveis, mas que não obscurecem o fato de que lutar por mais mulheres nas instâncias de poder significa a promoção da igualdade de acesso entre os gêneros, verdadeira promoção da democracia e real significado do espírito republicano. "A proporção de $15 \%$ de mulheres eleitas pode mudar a agenda política, mas $40 \%$ são necessários para que políticas adequadas às demandas femininas sejam introduzidas." (WäNGNERUd, 2009, p. 60, tradução nossa). Assim, representações descritivas e substantivas necessitam estar aliadas.

Quando, todavia, se constata que mulheres no poder nem sempre representam pautas femininas e sociais é revelada a outra armadilha criada pelo sistema patriarcal reinante, pois para aquelas que se engajam na política ascender a esses espaços é tarefa difícil, permanecer neles ainda mais e implantar pautas coerentes com as necessidades do gênero, pior ainda.

Encontrar o seu lugar de fala (Ribeiro, 2017), além de demandar um esforço numérico e reformador da estrutura política vigente, também exige das representantes eleitas à desconstrução de si. Se, a partir do momento que para estar ali precisarem agir como homens, como caricaturas estereotipadas do gênero masculino, que aceitam esse modus operandi para acessar minimamente o poder, essas mulheres em nada contribuem para transformar a representação descritiva em substantiva.

Mary Beard (2017) analisa esse processo também a partir do uso de terninhos pelas líderes femininas em que apesar de "serem convincentes e práticos; podem até significar a recusa em se tornar chamativas, o que é o destino de muitas esposas políticas; mas eles são também táticos - como abaixar o timbre da voz - para fazer o feminino aparentar mais masculino, para se encaixar na parte do poder. 16" (BEARD, 2007, p. 54-56, tradução nossa).

16 "[...]be convenient and practical; they may be a signal of the refusal to become a clothes horse, which is the fate of so many political wives; but they are also a simple tactic - like lowering the timbre of the voice - to make the female appear more male, to fit the part of power." 
Essa tática não é nada nova pois, "Elizabeth I [...] sabia exatamente qual era o jogo quando ela disse que tinha 'o coração e o estômago de um rei'. [...] Mulheres no poder são vistas como quebrando barreiras ou alternativamente como pegando algo que não lhes pertence ${ }^{17}$ ", (BEARD, 2007, p. 54-56, tradução nossa).

Dessa forma, a metamorfose que replica em um corpo feminino aspectos e, até mesmo, a mentalidade masculina não atende à premissa de igualdade, pelo menos, não em sua acepção material e no que se diferem as representações descritiva e substantiva.

Nesse momento, a sensação é de retorno a tempos anteriores quando, na sociedade Ilíria, localizada no Norte da Albânia existiam duas linhas de reprodução: a linha de sangue (pai, filho e avô) e a linha do leite (mãe, filha e avó), sendo a linha do sangue, a linha do poder (Stamile, 2016).

Para exercer o direito de reciprocidade, previsto no Código de Kanun, até hoje vigente, apenas representantes da linha de sangue podiam. Quando não havia representantes na linha de sangue para exercer esse direito, mulheres denominadas de virgens juramentadas se vestiam como homens para poder exercê-lo. Elas eram juramentadas perante 12 anciãos e não podiam contrair matrimônio, se vestiam como homens, podiam beber álcool e fumar e somente assim o direito de reciprocidade estaria garantido naquela família (Stamile, 2016).

Assim, as mulheres eleitas precisam perceber que o lugar que ocupam também lhes pertence. Pois, assumir a androgenia ou o estereótipo masculino para permanecer nesses espaços é cair na armadilha patriarcal e não há nada de revolucionário nisso, ainda que sua presença seja um grande avanço na luta contra o status quo.

17 "Elizabeth I [...] knew exactly what the game was when she said she had 'the heart and stomach of a king'. [...] Weakness comes with a female gender. [...] Women in power are seen as breaking down barriers, or alternatively as taking something to which they are not quite entitled." 


\section{MULHERES NA POLÍTICA: PANORAMA NACIONAL E INTERNACIONAL}

Para compreender como a sacralidade feminina implica em inefetividade dos direitos políticos (AgAmben, 2002) torna-se necessário analisar como mulheres que adentram ao cenário político nacional e internacional são tratadas e retratadas pela sociedade, pela mídia e pelo jogo político.

No Brasil, três casos recentes são emblemáticos dessa realidade: os ataques misóginos recebidos pela Deputada Maria do Rosário (PT-RS) e pela ex-Presidente Dilma Rousseff (PT) e o assassinato em 2018 da vereadora da cidade do Rio de Janeiro, Marielle Franco (PSOL).

Dentre as três mulheres, apenas a Deputada Federal Maria do Rosário permanece como representante do corpo político nacional. Em 2014, a Deputada foi verbalmente agredida pelo então “deputado federal Jair Bolsonaro do (PP-RJ) [que] afirmou que só não estupraria a deputada Maria do Rosário (PT-RS) porque ela 'não merece'. Maria do Rosário, ao se defender em entrevista à rádio Gaúcha, disse que foi agredida como mulher, parlamentar e mãe." (Morais; Souto, 2018, p. 37).

A ex-Presidente Dilma Rousseff, por sua vez, foi removida do posto ao qual foi reeleita, mediante controverso processo de impeachment, que: “[...] tornou possível o impeachment por crime de responsabilidade fiscal, sustentado nas denominadas pedaladas [...] e que, após a condenação do referido impeachment, passou-se a autorizar a abertura de créditos suplementares, por intermédio da Lei n. 13.332/16." (Souto, 2017, p. 103).

Além dessa agressão institucionalizada, a ex-Presidente Dilma Rousseff foi alvo de extensos ataques misóginos por meio de palavras de baixo calão perpetradas pelos manifestantes de seu governo. Os ataques à sua figura feminina não cessaram aí e, durante o procedimento de seu processo de impeachment, revista de grande alcance nacional 
publicou "capa intitulada As explosões nervosas da Presidente, a fim de denunciar a 'perda de condições emocionais' de Dilma Rousseff para manter-se no governo. [...]” (Bergamasco; Pardellas, 2016).

Dois anos após o processo de impeachment de Dilma Rousseff, outra mulher democraticamente eleita teve sua presença feminina violada. Marielle Franco, vereadora eleita pelo PSOL na cidade do Rio de Janeiro, foi responsável por realizar denúncias de abuso militar realizado na comunidade de Acari durante a intervenção federal na cidade do Rio de Janeiro e não tardou para que "no $26^{\circ}$ dia de intervenção militar - 14 de março de 2018, a voz feminina, LGBT, militante e negra de Marielle Franco fosse silenciada." (Morais; Souto, 2018, p. 46). Três anos após sua morte, ainda não se sabe quem a matou e os desdobramentos das investigações demonstram uma trama tortuosa para se chegar à verdade. Não bastasse a retirada abrupta da vida de uma representante política de uma das mais importantes cidades do mundo, a família de Marielle e todos aqueles que a admiravam tiveram que lidar com uma extensa divulgação de fake news, cujo propósito era contaminar seu legado e desviar o foco das investigações.

Após a morte de Marielle, uma campanha difamatória se espalhou pelas redes sociais e alguns protagonistas dessa onda de notícias falsas foram a desembargadora do Tribunal de Justiça do Rio de Janeiro (TJ-RJ) Marília Castro Neves, o deputado Alberto Fraga (DEM) e o Movimento Brasil Livre (MBL). [...] Uma das notícias falsas que mais repercutiu foi a postagem da desembargadora Marília Castro, que publicou em seu Facebook afirmando que Marielle "estava engajada com bandidos", acrescentando ainda que "a tal Marielle descumpriu 'compromissos' assumidos com seus apoiadores", referência à ligação da vereadora assassinada com o Comando Vermelho, facção de tráfico do crime organizado do Brasil. [...]Outra fake news amplamente divulgada foi a postagem publicada pelo deputado Alberto Fraga do Partido dos Democratas (DEM). O deputado, presidente da Frente Parlamentar de Segurança Pública, postou na sua conta do Twitter: "Conheçam o novo 
mito da esquerda, Marielle Franco. Engravidou aos 16 anos, ex-esposa do Marcinho VP, usuária de maconha, defensora de facção rival e eleita pelo Comando Vermelho, exonerou recentemente 6 funcionários, mas quem a matou foi a PM." (Lins; Lopes, 2018, p. 88-90).

Contudo, não se pode afirmar que o ataque à voz política feminina democraticamente eleita ocorra apenas no Brasil. Em 27 de março de 2017, Theresa May, à época Primeira Ministra do Reino Unido, durante visita a Escócia para tratar das negociações sobre o Brexit, teve reproduzido pelo jornal Daily Mail foto de capa sentada ao lado da premier da Escócia, Nicola Sturgeon, com a seguinte manchete: "Esqueça o Brexit, quem ganha nas pernas"18 (MALKin, 2017, tradução nossa). A reação ao machismo, à época, foi imediata pelos cidadãos britânicos, entretanto, o terreno hostil pós eleições que instauraram o Brexit, também levou à polarização e à violência política de gênero contra parlamentares britânicas.

Em outubro de 2019, seis parlamentares renunciaram ao cargo após ameaças. A parlamentar Nick Morgan, afiliada ao partido conservador inglês relatou que sua decisão decorria dos abusos sofridos em face de sua atuação política e dos impactos familiares que ela implicava. Heidi Allen, por sua vez, foi mais explícita sobre as ameaças sofridas e relatou o recebimento de mensagens hostis tanto pela internet quanto nas ruas inglesas. Sua situação evoluiu para a perseguição, de forma que Heidi Allen precisou instalar alarmes em sua residência. Além de ser diagnosticada com síndrome do pânico, pois mesmo após a prisão de seu perseguidor, a parlamentar não conseguiu se restabelecer e optou pela renúncia ao cargo (Parlamentares..., 2019).

Todos esses exemplos demonstram a crescente da denominada violência política de gênero que, neste momento, sai da esfera privada quando se tem a "situação do cônjuge que não permite que sua

18 "Never mind Brexit, who won Legs-it!" 
esposa concorra a um cargo político." (BIANCHINI, 2014) e atinge a esfera pública sendo conceituada, nos termos do art. $3^{\circ}$, da Lei Modelo criada pela Organização dos Estados Americanos (OEA), como o propósito de inviabilizar o exercício dos direitos políticos das mulheres, seja por meio de condutas comissivas ou omissivas que baseadas no gênero da vítima se destinam a causar dano a uma mulher ou a uma coletividade de mulheres. São condutas praticadas de forma direta ou mediante terceiros, comportando diversas modalidades, "mas que não se limitam a, violência física, sexual, psicológica, moral, econômica ou simbólica ${ }^{19} . "$ (OEA, 2017, p. 23, tradução nossa).

A lesividade dessa conduta é tanto quanto as demais formas de violência de gênero (violência doméstica, psicológica, patrimonial e feminicídio), pois além da vítima compromete o futuro de milhares de mulheres que sem a adequada representação na arena política continuam a mercê do domínio masculino. Diante disso, a Bolívia editou em 2012, após o assassinato da vereadora Juana Quispe, a Lei n. 243, "que prevê sentenças de prisão de dois a cinco anos para quem pressiona, persegue, assedia ou ameaça uma mulher que exerce funções públicas, e até oito anos de prisão por cometer agressão física, psicológica ou sexual.” (ONU Mulheres, 2019).

Em outra ponta, também há algumas líderes femininas que adquiriram maior sucesso no ambiente político, ainda predominantemente masculino, e que ganham destaque na busca por representação feminina na política, sendo vistas como símbolos de esperança. Dentre elas, destacam-se a Chanceler alemã Angela Merkel que lidera o país desde 2005.

Aliada de Merkel, Ursula von der Leyen também encampa uma nova realidade para as mulheres na política sendo a primeira mulher eleita a Presidente da Comissão Europeia e que possui a ambição de criar uma comissão igualitária de gênero.

19 "but is not limited to, physical, sexual, psychological, moral, economic or symbolic violence." 
Com esse mesmo intuito, ascende ao Parlamento finlandês a Primeira Ministra Sanna Marin que com apenas 34 anos de idade foi eleita a chefe de governo mais jovem no mundo. Igualmente, jovem é também a Primeira-Ministra da Nova Zelândia que diante do sucesso de seu país no controle à pandemia de coronavírus desponta interna e externamente como uma grande líder política.

Contudo, os exemplos e reflexões aqui propostos ainda não alteram o status quo, se observado que além da severa sub-representação, as mulheres que ocupam cargos de liderança, seja no Legislativo ou no Executivo de países em desenvolvimento como o Brasil ou nas grandes potências mundiais, ainda no século XXI enfrentam a dificuldade em saber como é ser uma mulher na política.

Assim, o desafio em ser mulher em espaços de poder e tomada de decisões percorre os mais diferentes cenários, contextos e sociedades e nem quando vemos uma mulher no poder enquanto líder de uma grande Nação, quer dizer que ela - em seu eu mais absoluto - está lá.

A luta, portanto, por real igualdade de representação perpassa por toda uma remodelação social em que se anseia que Ursula von der Leyen, Sanna Marin, Jacinta Adern e outras tantas emergentes mulheres políticas sejam capazes de implantar em seus Parlamentos e governos.

\section{CONCLUSÃO}

Com a proposta de apresentar os desafios na concretização da igualdade de gênero na participação política, o presente artigo conclui que o Brasil está longe de conseguir garantir voz pública e política às mulheres e com isso conferir efetividade à igualdade que seu texto constitucional disciplina. Pois, enquanto existe o avanço numérico na representação feminina, alcançado nas últimas eleições, ainda há o boicote à figura feminina democraticamente eleita e, nesse aspecto, precisa ficar claro que o País não está sozinho. 
Medidas adotadas como, por exemplo, as políticas de cotas de gênero que ao final são ignoradas pelos partidos políticos, por meio de estratégias que criam "candidaturas laranjas" ou o aumento proforma no número de mulheres quando, de fato, o que ocorre no dia-a-dia do exercício de seus mandatos é o desrespeito, significam que esse mecanismo produz pouco ou nenhum avanço em políticas públicas que garantam efetiva participação feminina se não houver o real compromisso na execução dessa política afirmativa.

Encarar o aumento do número de mulheres nas bancadas legislativas como uma vitória em prol da igualdade é postura ingênua, pois como descrito, grande parte daquelas que ocupam esses cargos são impedidas por diversos meios misóginos de realizarem suas pautas e agendas políticas. Além do fato de que, em alguns países, como o exemplo de Ruanda ter muitas mulheres no Parlamento não significa real acesso ao poder.

Existe, portanto, a necessidade urgente de encarar que o Estado brasileiro ainda não concedeu às mulheres o real e efetivo direito de serem eleitas e que muito precisa ser feito para mudar essa realidade.

\section{REFERÊNCIAS}

AGAMBEN, Giorgio. Homo Sacer: o poder soberano e a vida nua I. Belo Horizonte: Editora UFMG, 2002.

AGAMBEM, Giorgio. Estado de Exceção. Trad. Iraci D. Poleti. São Paulo: Boitempo, 2004.

AGAMBEN, Giorgio. Estado de Excepción y Genealogía del Poder. Barcelona: Centro de Cultura Contemporânea de Barcelona, 2011.

BARBIERI, Catarina Helena Cortada; RAMOS, Luciana de Oliveira (coord.). Democracia e representação nas eleições de 2018: campanhas eleitorais, financiamento e diversidade de gênero: relatório final (2018-2019). São Paulo: FGV Direito SP, 2019. Disponível em: http://bibliotecadigital. fgv.br/dspace/bitstream/handle/10438/27646/RELAT\%c3\%93RIO\%20 
FINAL $\% 202018-2019$. pdf? sequence $=5$ \&isAllowed $=\mathrm{y}$. Acesso em: 25 jul. 2020.

BEARD, Mary. Women \& Power: A Manifesto. London: Review of Books, 2017.

BERGAMASCO, Débora; PARDELLAS, Sérgio. Uma Presidente fora de si. Revista Isto é. 01 abr. 2016. Disponível em: https://istoe.com.br/450027_ UMA+PRESIDENTE+FORA+DE+SI/. Acesso em: 12 mai. 2020.

BIANCHINI, Alice. A violência política como uma das formas de violência de gênero. Jusbrasil, 2014. Disponível em:https://professoraalice.jusbrasil. com.br/artigos/143456023/a-violencia-politica-como-uma-das-formas-de-violencia-de-genero. Acesso em: 24 abr. 2020.

FEOLA, Silvia. Zoon politikon: a condição natural da autoridade. Faculdade de Filosofia, Letras e Ciências Humanas. Departamento de Filosofia, Universidade de São Paulo, 2012.

FOUCAULT, Michel. Segurança, território, população: curso dado no Collège de France (1977-1978). Trad. Eduardo Brandão. São Paulo: Martins Fontes, 2008.

HINOJOSA, Magda; PISCOPO, Jennifer. Promoting Women's Right to Be Elected: Twenty-Five Years of Quotas in Latin America, 2013. Disponível em: https://jenniferpiscopo.files.wordpress.com/2013/09/hinojosa-piscopo-final-english.pdf. Acesso em: 19 out. 2019.

HOMERO. Odisséia. Tradução de Carlos Alberto Nunes. 4. ed. Rio de Janeiro: Ediouro, 2001.

INSTITUTO ALZIRAS (org.). Perfil das prefeitas no Brasil: mandato 2017-2020. Rio de Janeiro: Instituto Alziras, 2018.Disponível em: https:// oig.cepal.org/sites/default/files/perfil_das_prefeitas_do_brasil_2017-2020. pdf. Acesso em: 15 fev. 2020.

INTER-PARLIAMENTARY UNION (IPU). Women in parliament: 1995-2020 - 25 years in review. Available at: https://www.ipu.org/resources/publications/reports/2020-03/women-in-parliament-1995-2020-25years-in-review\#: :text $=$ The $\% 20$ overall $\% 20$ percentage $\% 20$ of $\% 20$ women,11.3\%20per\%20cent $\% 20$ in $\% 201995$.\&text $=$ The $\% 20$ IPU $\% 20$ has $\% 20$ tracked $\% 20$ women's, historical $\% 20$ trends $\% 2 \mathrm{C} \% 2$ progress $\% 20$ and $\% 20$ setbacks. Access: 19 Jul. 2020. 
LINS, Eunice Simões; LOPES, Flávia. Trevas e queda: análise do imaginário feminino na representação de fake news sobre Marielle Franco. Revista Memorare, Tubarão, v.5, n.1, pp. 78-96 jan./abr. 2018. Disponível em: http://portaldeperiodicos.unisul.br/index.php/memorare_grupep/article/ view/6302/3814. Acesso em: 03 jun. 2018.

MALKIN, Bonnie. Daily Mail "Legs-it" front page criticized as "sexist, offensive and moronic". The Guardian, 28 mar. 2017. Disponível em: https://www.theguardian.com/media/2017/mar/28/daily-mail-legs-it-front-page-sexist. Acesso em: 17 set. 2019.

MILL, John Stuart. A Sujeição das mulheres: texto integral. São Paulo: Escala, 2006.

MILL, John Stuart. Dissertations and Discussions: Political, Philosophical and Historical, vol. IV. New York: Henry Holt, 1874.

MORAIS, Clarice Paiva; SOUTO, Luana Mathias. Seletividade permanente: o feminino no estado de direito brasileiro. In: CORGOZINHO, Mariana Lara; MAGALHÃES, José Luiz Quadros de; COSTA JUNIOR, Ernane Salles da. (Org.). Eurocentismo e Resistência: perspectivas críticas. Porto Alegre: Simplíssimo, 2018.

NAKAMURA, Luis Antonio Corona; SALGADO, Eneida Desiree. Mulheres e política no México e no Brasil. Seqüência - Estudos Jurídicos e Políticos, v. 41, n. 85, 2020, p. 112-134. Disponível em: https://periodicos. ufsc.br/index.php/sequencia/article/view/75372. Acesso em 12 jul. 2021.

NUNES, Marilene Aparecida; BONINI, Altair. Bertha Lutz e a conquista do voto feminino no Brasil: ensino de história e as relações de poder e gênero. Cadernos Dia a dia da educação. Disponível em: http://www.diaadiaeducacao.pr.gov.br/portals/cadernospde/pdebusca/producoes_pde/2010/2010_ fafipa_hist_artigo_marilene_aparecida_nunes.pdf. Acesso em: 15 fev. 2020. ONU MULHERES. ATENEA: por uma democracia 50/50. 2020. Disponível em: http://www.onumulheres.org.br/wp-content/uploads/2020/09/ ATENEA_Brasil_FINAL23Sep.pdf. Acesso em: 10 out. 2020.

ONU MULHERES. Em toda a América Latina, as mulheres lutam contra a violência na política. 10 jan. 2019. Disponível em: http://www. onumulheres.org.br/noticias/em-toda-a-america-latina-as-mulheres-lutam-contra-a-violencia-na-politica/. Acesso em: 22 mai. 2020. 
ORGANIZATION OF AMERICAN STATES (OEA). Inter-American Model Law On The Prevention, Punishment and Eradication of Violence Against Women in Political Life. 2017. Disponível em: http://www. oas.org/en/mesecvi/docs/LeyModeloViolenciaPolitica-EN.pdf. Acesso em: 20 set. 2020 .

PARLAMENTARES mulheres renunciam após ameaças no Reino Unido. UOL Notícias, 31 out. 2019. Disponível em: https://noticias.uol.com.br/ internacional/ultimas-noticias/2019/10/31/parlamentares-mulheres-renunciam-apos-ameacas-no-reino-unido.htm?. Acesso em: 01 nov. 2019.

PHILLIPS, Anne. The Politics of Presence. Oxford: Clarendon Press, 1998. PITKIN, Hanna Fenichel. El concepto de representation. Madrid: Centro de Estudios Constitucionales, 1985.

REEVES, Arin N. Mansplaining, Manterrupting and Bropropriating: Gender Bias and the Pervasive Interruption of Women. Chicago: Nextions, 2015. Disponível em: http://nextions.com/wp-content/uploads/2017/05/ manterruptions-bropropriation-and-mansplaining-2-yellow-paper-series. pdf. Acesso em: 22 Out. 2019.

RIBEIRO, Djamila. O que é o lugar de fala? Belo Horizonte: Letramento, 2017.

SAMPAIO, José Adércio Leite. Direitos fundamentais: retórica e historicidade. 2 ed. Belo Horizonte: Del Rey, 2010.

SOUTO, Luana Mathias. Do Tiranicídio ao impeachment: as formas de destituição do poder. 2017, 126 f. Dissertação (Mestrado) - Pontifícia Universidade Católica de Minas Gerais, Programa de Pós-Graduação em Direito, Belo Horizonte, 2017. Disponível em:< http://www.biblioteca. pucminas.br/teses/Direito_SoutoLM_1r.pdf >. Acesso em: 09 jun. 2018.

STAMILE,Natalina. Mujeres por naturaleza y hombres por elección. Libro de Actas del I Congreso de jóvenes investigadorxs con perspectiva de género (Getafe, 16 y 17 de junio de 2016). Instituto Universitario de Estudios de Género, Universidad Carlos III de Madrid, 2016. Disponível em:https://e-archivo.uc3m.es/bitstream/handle/10016/24071/ mujeres_stamile_IJCPDG_2016.pdf?sequence $=1 \&$ isAllowed $=y$. Acesso em: 30 mai. 2020.

TREMBLAY, Manon. Democracy, Representation, and Women: A Comparative Analysis, Democratization. Journal Democratization, vol. 14, 2007. 
UVUZA, Justine N. Hidden Inequalities: Rwandan Female Politicians' Experiences of Balancing Family and Political Responsibilities. 2014, $255 f$. Tese (Doutorado) - Universidade de Newcastle, Faculdade de Geografia, Políticas e Sociologia, Newcastle upon Tyne, 2014. Disponível em: https:// theses.ncl.ac.uk/jspui/handle/10443/2475. Acesso em: 30 ago. 2020.

WÄNGNERUD, Lena. Women in Parliaments: Descriptive and Substantive Representation. Annual Review of Political Science, 12, 2009, p. 51-69. Disponível em:https://www.annualreviews.org/doi/pdf/10.1146/annurev. polisci.11.053106.123839. Acesso em: 23 Out. 2019.

WYLIE, Kristin; SANTOS, Pedro dos; MARCELINO, Daniel. Extreme non-viable candidates and quota maneuvering in Brazilian legislative elections. Opinião Pública, Campinas, v. 25, n. 1, jan-abr, 2019, P. 1-28. Disponível em: https://www.scielo.br/scielo.php?script=sci_arttext\&pi$\mathrm{d}=$ S0104-62762019000100001. Acesso em: 04 set. 2020.

\section{LUANA MATHIAS SOUTO}

Doutoranda e Mestre em Direito Público pela Pontifícia Universidade Católica de Minas Gerais. Bolsista PROEX Capes/Taxa. Bolsista CAPES/PDSE na Universidade de Vechta/Alemanha. O presente trabalho foi realizado com apoio da Coordenação de Aperfeiçoamento de Pessoal de Nível Superior - Brasil (CAPES) Código de Financiamento 001.

Endereço profissional: Avenida 31 de março, n. 1020 - Prédio 93

- Dom Cabral - Belo Horizonte/MG CEP: 30535-000

ORCID ID: https://orcid.org/0000-0002-6961-0187

E-MAIL: luana.mathias.souto@gmail.com

\section{JOSÉ ADÉRCIO LEITE SAMPAIO}

Doutor e Mestre em Direito Constitucional pela UFMG. Pós-doutorado pela Universidad de Castilla la Mancha. Professor da PUC-MG e ESDHC. Procurador da República. 
Endereço professional: Avenida 31 de março, n. 1020 - Prédio 93

- Dom Cabral - Belo Horizonte/MG CEP: 30535-000

ORCID ID: https://orcid.org/0000-0002-9452-4811

E-MAIL: joseadercio.contato@gmail.com

Recebido: 01/11/2020

Aceito: 05/09/2021

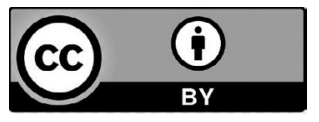

Este trabalho está licenciado sob uma licença Creative Commons Attribution 4.0 International License.

Autores e autoras cedem à Revista Sequência direitos exclusivos de primeira publicação, ficando o trabalho licenciado sob a Creative Commons Attribution 4.0 International License. A licença autoriza que terceiros remixem, adaptem e ou criem a partir do trabalho publicado, indicando o crédito ao trabalho original e sua publicação inicial. Os autores têm permissão para assumir contratos adicionais em separado, com distribuição não exclusiva da versão publicada na Revista Sequência, indicando, de todo modo, a autoria e publicação inicial neste periódico. 